$\xi=1$

\title{
A conceptual framework for facilitating optimal functioning by survivors of cerebro-vascular accidents and their caregivers at home in Oshana Region, Namibia
}

\author{
Suama W Kuugongelwa *, Louis F Small \\ Institution: University of Namibia, Private Bag13301; Windhoek: Namibia \\ *Corresponding author E-mail: skuugongelwa@unam.na
}

\begin{abstract}
Providing care for the survivors of a cerebro-vascular accident in home settings is an increasingly common practice. Accordingly, a conceptual framework was developed with the aim of establishing guidelines for the implementation of a support programme to enable survivors and their caregivers to function optimally at home. The framework involves the attributes of the agent (lecturer as a facilitator), the recipients (survivors and caregivers), the context (the home setting), the procedures for enabling optimal functioning and, finally, the terminus, which is defined at optimal functioning for both the survivors and their caregivers.
\end{abstract}

Keywords: Agent; Recipient; Context; Procedure; Terminus.

\section{Introduction}

This conceptual framework was developed on the basis of Dickoff, James and Wiedenbach's (1968) nursing theory (as extracted from the author's original study titled "An educational programme to support survivors of cerebro-vascular accidents and their caregivers at home"). The situation analysis conducted in this study revealed that the survivors and their caregivers were in need of guidance and support. An educational support programme was subsequently developed to establish a routine of daily activities for managing survivors at home. This takes into consideration their functional limitations and disabilities, as well as assisting caregivers to cope. However, this programme required a conceptual framework as a prerequisite, which is what this article focuses on (Rittman, Faircloth, Boylstein, Gubrium, Williams, Van Puymbroek et al., 2004).

The survey list, which encompasses context, agent, recipient, dynamics, procedure of the activity and terminus, as advocated by Dickoff et al. (1968, p. 433), was used to describe the framework for conducting this study.

In this study, the agent who performs the activity is the researcher, who has to facilitate learning and assist with the achievement of optimal functional abilities. The recipients are the survivors and their caregivers, while the home setting forms the context in which the survivors and caregivers interact (procedures) and adapt. The dynamics are the forces anticipated that will enable them to change and/or adhere to the programme in order to achieve optimum functioning, which in terms of this framework is regarded as the terminus.

\section{Purpose}

The purpose of this conceptual framework for a home-based health care programme with multi-component interventions was to draw together all the possible determinant factors and the coping methods required by the caregivers and the survivors of cerebrovascular accidents and to describe them. The application of this conceptual framework subsequently resulted in the development and implementation of an educational programme. This programme will not be addressed in this article.

\section{The components of the conceptual frame- work}

\subsection{Agent: researcher}

The first component to be described is the agent who would provide the activity, that is, the implementation of a support programme for the survivors of cerebro-vascular accidents and their caregivers which is intended to enable them to function optimally at home. This agent function requires that he or she possess the personal qualities needed to build good interpersonal relationships with the recipients. Secondly, the agent, who in this case is a nurse lecturer, should have a clearly identifiable educator role together with home nursing care abilities in order to guide and support the survivors and their caregivers in the home setting (Humphreys, Gidman, \& Andrews, 2006). This would result in improvement and empowerment regarding the knowledge and self-care of the survivors and their caregivers.

Furthermore, the agent should possess the following characteristics, which were applied to the context of this study in order to empower and support the survivors and their caregivers:

- Competency. According to Cook (2007), the agent has to have expert clinical knowledge and skills for her role as a lecturer, as well as for guiding and supporting the survivors of cerebro-vascular accidents and their caregivers in facilitating optimal functioning at home. 
- Open-mindedness. In concurrence with the suggestions made by Sellman (2003) and Ayers, Bruno, and Langford (2003), the open-minded agent has respect and tolerance for diverse ideas, and is open to the views of others without compromising the client's safety.

- Empathy. This is an essential characteristic in relationships with survivors of cerebro-vascular accidents and their caregivers. Empathy allows the agent to recognise and to some extent share the emotions of others and to understand the meaning and significance of a particular behaviour (Glanze, Anderson, Anderson, Urdang, \& Swallow, 2004).

- Perseverance and courage are the primary determinants of professional success. In this study, as maintained by Tye (2005), perseverance gives the agent the clarity to know what is right and to keep on doing the right thing irrespective of obstacles.

- Courage, commitment and confidence. The agent has to be courageous, which implies that she or he should set an example by not giving up easily. Commitment implies providing the extra effort needed to meet the needs not only of the survivors but also the caregivers. Being confident, on the other hand, implies that the agent has to value her own strengths and to be open to opportunities for improvement (Bulley 2006; Rinaldi, 2005; Satkowski, 2006).

- Caring. The agent must be caring, that is, be able to show empathy, compassion and sensitivity in the delivery of relevant nursing and health care services (American Association of Colleges of Nursing, 2006).

- Trust and a respectful relationship. Trust is the foundation of all successful interpersonal relationships. It implies ability on the agent's part to join with the survivors of cerebrovascular accidents and their caregivers in overcoming the inability to function optimally at home (O'Neil, 2007).

In conclusion, the agent, here the researcher, is the person who provides the support programme for facilitating optimal functional abilities for the survivors of cerebro-vascular accidents and their caregivers at home. This requires establishing a special relationship with the recipients. It also requires qualities such as competency, open-mindedness, empathy, perseverance, courage, commitment, confidence, caring, trust and respectful relationships.

\subsection{Recipient: the survivors of cerebro-vascular acci- dents and their caregivers}

Recipient is defined as a person who receives something (Compact Oxford English dictionary, 2003). In the milieu of this study, the recipients were the survivors of cerebro-vascular accidents and their caregivers, who lacked the knowledge and skills required for optimal functioning at home. In order for these people to be the recipients of the support programme and the implementation guidelines, they needed to revisit their day-to-day relationships, the characteristics that were required from them in order to function optimally and the behaviour changes needed to be committed to applying the knowledge and skills to optimal functioning at home.

In order for the recipients to perform optimally at home, they should possess certain characteristics:

- Curiosity. The survivors of cerebro-vascular accidents and their caregivers should show intellectual curiosity by demonstrating a desire for more information about optimal functioning at home (Miller, 2003).

- Decision-making abilities. The survivors and their caregivers should be able to initiate, decide and maintain continued self-care.

- Motivation. This characteristic is a combination of desires, values and beliefs that drives the survivors and their caregivers to take and maintain action.

- Good interpersonal relationships and communication. Good interpersonal relationships are critical for the sound imple- mentation of optimal functioning and are based on effective and open communication (Miller, 2003).

- Enthusiasm. If the survivors and their caregivers are enthusiastice they will strive to improve their abilities despite the many factors that influence the environment negatively.

- Responsibility. The survivors and their caregivers have to take responsibility for the application of the programme for optimal functioning at home (Lambert \& Lambert, 2003).

In summary, the survivors and caregivers are functioning within a home environment that is bound to routines, individual roles and social relationships and interaction. It is therefore important to promote good interpersonal relationships and communication in order for optimal functioning to be realised by the recipients.

\section{Context: home setting}

A home is defined as the place where one lives (Compact Oxford English dictionary, 2003). According to the Word thesaurus (computer tool), context is a situation, a framework, a milieu, an environment or a background. In the perspective of this study, the context is defined as the environment or milieu consisting of the home of the family where the study was conducted, as well as the cultural values and beliefs that guided the functions to be optimally performed and the family's characteristics, social interaction and social control, which provided the framework for the home setting.

Therefore, the support programme should enable the survivors and their caregivers to apply basic family functions, such as affection, security, identity, affiliation, socialisation and being in control, to help them perform their basic roles at home.

\section{Dynamics: disability}

Dynamics are the forces at work that could lead to change. In this study, the dynamics centred largely on the survivors' inability to self-care after the incident, their altered role function and performance, their disrupted social interactions and their negative emotions resulting from altered self-esteem. On the other hand, dynamics relating to the caregivers involved their negative experiences such as the disruption of their lifestyle and their disturbed sleeping patterns, as well as the financial challenges experienced. At home, survivors and caregivers are expected to function independently and to be self-reliant. When survivors and caregivers feel that their ability to function is their own responsibility, they will take a much more active interest in promoting it (Greveson \& James, 2004). This in turn results in their taking responsibility for developing their own health potential, which is referred to as "self-care" (Stein \& LeNavenec, 2004). Hence, the purpose of the support programme in the context of this study is to assist the survivors of cerebro-vascular accidents and their caregivers to return to or reach a level where they can attain abilities for optimal functioning and assume responsibility for maintaining them.

\section{Procedure: interactive facilitation}

A procedure is defined in the Merriam Webster Dictionary (2015) as a series of actions that are done in a certain way or order: an established or accepted way of doing something. In the context of this study, interactive facilitation is a procedure through which optimal functional abilities may be enabled. This enablement involves mutual and purposeful interaction between the survivors and their caregivers in order to bring about optimal functioning at home.

The execution of these procedures will engage survivors and caregivers in reframing their own knowledge and skills, as well as their negative emotions, in order to modify daily routines and adjust to social relationships. As an outcome, this increases caregiving satisfaction and brings about an improved standard of functional ability at home. 


\section{Terminus: optimal functioning at home}

Terminus is the ultimate goal of the procedure. In the context of this study, the terminus was optimal functioning at home. Optimal functioning at home with a survivor of a cerebro-vascular accident requires the family to adapt and to renegotiate various roles in order to maintain the equilibrium. The aim of this article was to report on the development of a conceptual framework to facilitate a support programme for survivors and their caregivers at home. The survivors and their caregivers should in turn implement this programme in order to modify their way of life through adjustment, stabilisation and coping. The result of this would be that in a functional family the members would adapt and change both their roles and expectations, so that they can assume the responsibilities required to assist the disabled member.

\section{Conclusion}

This article has defined and discussed the components of a conceptual framework for developing a support programme for the survivors of cerebrovascular accidents and their caregivers in order to enable optimal functioning at home. The components are identified as an agent (the researcher/facilitator) for the programme, the recipients, the context, the procedure - the specific interventions for facilitating optimal functioning - and the terminus, at which point the survivors and caregivers should be able to function optimally at home.

\section{Acknowledgements}

This article has been extracted from the author's main study "An educational programme to support survivors of cerebro-vascular accidents and their caregivers at home". This study was completed with the permission of the Ethical and Research Committee of the Namibian Ministry of Health and Social Services, the Oshana Regional Health Director and the office of the Oshana Regional Council. Special thanks are extended to the editor of this article.

\section{References}

[1] American Association of Colleges of Nursing. (2006). Essentials of baccalaureate education for professional nursing practice (pp. 89). Washington, DC: American Association of Colleges of Nursing.

[2] Ayers, M., Bruno, A.A., \& Langford, R.W. (2003). Community based nursing care: Making the transition. St. Louis, MO: Mosby.

[3] Bulley, M. (2006). Leading with confidence. Middlesex, UK: Nursing Standard Classified.

[4] Compact Oxford English dictionary. (2003). (2nd ed.). New York: Oxford University Press.

[5] Cook, C. B. (2007). Initial and continuing competence in education and practice: Overview and summary. Online Journal of Issues in Nursing. Retrieved August 15, 2009 from http://www.nursingworld.org/ojin/topic $10 \mathrm{ntr} . \mathrm{htm}$

[6] Dickoff, J., James, P., \& Wiedenbach, E. (1968). Theory in a practice discipline: Part 1. Practice oriented theory. American Journal of Nursing Company. Nursing Research, 17(5), SeptemberOctober, 415-444. http://dx.doi.org/10.1097/00006199-19680900000006.

[7] Glanze, W. D., Anderson, K. N., Anderson, L. E., Urdang, L., \& Swallow, H. H. (2004). Mosby's medical and nursing dictionary. St Louis, MO: Mosby.

[8] Greveson, G., \& James, O. (2004). Improving long-term outcome after stroke: The views of patients and carers. Health Trends, 23, $161-162$.

[9] Humphreys, A., Gidman, T., \& Andrews, M. (2006). The nature and purpose of the role of the nurse lecturer in practice settings. Nurse Education Today, 20, 311-317. http://dx.doi.org/10.1054/nedt.1999.0453.

[10] Lambert, V. A., \& Lambert, C. E. (2003). Psychosocial care of the physically ill: What every nurse should know (2nd ed.). Englewood Cliffs, NJ: Prentice-Hall.
[11] Merriam Webster Dictionary. (2015). An Encyclopaedia Britannica Company.

[12] Miller, J. F. (2003). Coping with chronic illness: Overcoming powerlessness (2nd ed.). Philadelphia, PA: FA Davis.

[13] O'Neil, P. (2007). Nursing in the next century. In E. O'Neil \& J. Coffman (Eds), Strategies for the future of nursing (pp. 222-223). San Francisco, CA: Jossey-Bass.

[14] Rinaldi, D.M. (2005). The lived experience of commitment to nursing: as perceived by nurses in their nursing environment.Columbia: Columbia University Teachers College.

[15] Rittman, M., Haircloth, S., Boylstein, C., Gubrium, J. F., William, C., Van Puymbroeck, M., \& Ellis, C. (2004). The experience of time in the transition from hospital to home following stroke. Jour nal of Rehabilitation Research \& Development, 41(3A), 259-268. http://dx.doi.org/10.1682/JRRD.2003.06.0099.

[16] Satkowski, T. (2006). Courage, success wins of admirers nursing. Arkansis: University of Arkansas for Medical Sciences.

[17] Sellman, D. (2003). Open-mindedness: A virtue for professional practice. Nursing Philosophy, 4(4), 17-24. http://dx.doi.org/10.1046/j.1466-769X.2003.00113.x.

[18] Stein, G., \& LeNavenec, C-L. (2004). a discharge care plan for the elderly diabetic client: An application or Orem's Self Care Model and evidence-based nursing interventions (Electronic version). Canada Nurses. Retrieved September 26, 2009, from http://://juns.nursing.arizona.edu/articles/Fall \% 202004/stein

[19] Tye, J. (2005). Never fear, never quit. Nursing Management, July. 